\title{
Variation and Phenotypic Evaluation of Intraspecific Oryza glaberrima Lines Resulting from Crossings between Tog5681, $\operatorname{Tog} 5672$ and $\operatorname{Tog} 7291$
}

\author{
Yves Agnoun ${ }^{1}$, E. Ahounou ${ }^{2}$, M. Sié ${ }^{3}$, S. A. Ogunbayo ${ }^{3}$, B. Toulou ${ }^{3}$, K. Futakuchi ${ }^{3} \&$ A. Ahanchédé ${ }^{1}$ \\ ${ }^{1}$ Faculty of Agricultural Sciences, University of Abomey-Calavi, 01 BP 526, Cotonou, Benin \\ ${ }^{2}$ Faculty of Science and Technics, University of Abomey-Calavi, 01 BP 526, Cotonou, Benin \\ ${ }^{3}$ Africa Rice Center, 01 BP 2031, Cotonou, Benin \\ Correspondence: Yves Agnoun, Faculty of Agricultural Sciences, University of Abomey-Calavi, 01 BP 526, \\ Cotonou, Benin. Tel: 229-9708-9577. E-mail: yagnoun@yahoo.fr
}

Received: March 20, 2012 Accepted: May 3, 2012 Online Published: August 15, 2012

doi:10.5539/jps.v1n2p129 URL: http://dx.doi.org/10.5539/jps.v1n2p129

\begin{abstract}
Rice cultivation in Africa suffers from various biotic and abiotic constraints. The African rice, Oryza glaberrima, is a potential source of useful genes for resistance to a range of these stresses. The development of interspecific varieties based on crosses between the high yielding cultivated Asian rice species (Oryza sativa) and O. glaberrima showed some gaps in the resistance compared to O. glaberrima. In order to valorize its genetic potential, intraspecific lines were developed using three $O$. glaberrima lines Tog5681, Tog5672 and Tog7291 as parents. Phenotypic evaluation of the progeny (total of $55 \mathrm{~F}_{6}$ lines) and checks $(O$. glaberrima and $O$. sativa) using 18 quantitative characters, showed a higher degree of variation in plant height, leaf dimensions, panicle fertility and grain weight. Based on the discriminating characters proposed here for further exploitation, intraspecific lines were grouped into five clusters, two of which (G4 and G5) contained the best lines for vegetative (G4) and productive (G5) characters.
\end{abstract}

Keywords: Oryza glaberrima, intraspecific, evaluation, phenotypic diversity, varietal improvement

\section{Introduction}

Rice is one of the main stands of global food security and has thus been one of the main focuses of international research for several decades. It is a staple food of about half of the world's population living in Asia and Africa, providing 40 to $70 \%$ of their total food calories. In Africa, it is one of the most important food crops and its consumption growth rate is higher than the population growth rate. The estimated annual global rice production was about 688 million tons in 2008 and 689 million tons in 2009 on about 149 million hectares (FAO, 2009). However, despite this strong growth in production, there is a growing demand for rice mainly due to demographic increase, rapid urbanization, increased proportion of rice in the population's diet, especially those of Africans and new end-users (livestock feed, breweries, processors and agri-business farmers etc.). It is expected that this demand will continue to grow. Yet, among the millions of people suffering from chronic hunger throughout the world, over $50 \%$ live in areas dependent on rice production. Moreover, about $80 \%$ of small-scale rice farmers, generally poor, contribute to the world's rice production primarily to increase their incomes and satisfy their family needs, but also to improve human consumption and his health well-being (FAO, 2004).

In Africa, rice cultivation suffers from a number of constraints, such as weeds competition, salinity, nitrogen nutrition, iron toxicity, pests and diseases, which severely affect rice productivity (Thiémélé et al., 2010; Sahrawat \& Sika, 2002; Fofana \& Rauber, 2000). To cope with these stresses, interspecific hybridization were used by the Africa Rice Center (AfricaRice) to develop new rice varieties known as NERICA (New Rice for Africa), starting from crossings between the two cultivated rice species Oryza glaberrima and Oryza sativa (Jones et al., 1997). In general, this interspecific breeding program aimed to combine the positive characteristics of the cultivated African rice $O$. glaberrima resistance genes, and weed competitiveness due to early growth vigor, high tillering ability, large leaf area and droopy leaves with the high yielding ability of the Asian rice $O$. sativa. The high grain productivity of the Asian species is due mainly to its fertile and rich panicles with 
secondary branches, erect leaves, without plant lodging or grain shattering. The interspecific breeding program provided AfricaRice scientists an opportunity to improve the agronomic potentialities of $O$. sativa, including its two sub-species japonica and indica. It also provided access to the $O$. glaberrima genome and enabled the introgression of minor oligogenic genes into the Asian varieties, which had hitherto had very limited success (Jones et al., 1997; Ndjiondjop et al., 2008; Agnoun et al., 2012). The current NERICA varieties are inferior to $O$. glaberrima in terms of weed-competitiveness (Rodenburg et al., 2009), resistance to rice insect pests and diseases and are more similar to $O$. sativa than $O$. glaberrima in relation to morphological characteristics at both vegetative and reproductive growth stages.

Recent findings by AfricaRice scientists and their partners, especially breeders, agronomists and nutritionists, have sparked renewed interest in the cultivated African rice species O. glaberrima (Sarla, 2005; Joho et al., 2008; Futakuchi \& Sié, 2009; Mohapatra, 2010, 2011; Moukoumbi et al., 2011). Indeed, O. glaberrima has proved to be a rich source of resistance genes for rice production constraints in West and Central Africa (WCA), e.g. resistance to the rice yellow mottle virus (RYMV), cannot be found easily in the variation of $O$. sativa.

Although since several scientific studies have revealed the genetic importance of $O$. glaberrima, AfricaRice is still seeking outstanding $O$. glaberrima genotypes and a good alternative way to better exploit its useful genetic assets. In this regard, two alternative breeding pathways have been suggested: (i) the first possibility for developing NERICA varieties with good introgression of the African rice genome is backcrossing to the $O$. glaberrima parent. However, there is no influence of the O. glaberrima parent on the yielding ability of the existing NERICA lines; (ii) the second way, which was adopted in the present study, is to develop intra-specific O. glaberrima breeding varieties. According to Futakuchi and Sié (2009), and Sié et al. (2012), the second breeding method is the best way to exploit the unique assets of the cultivated African rice multiple resistances to major WCA constraints, for instance because fixed fertile progeny can be obtained without suffering from a sterility barrier that always crops up in interspecific breeding. Following the overall breeding concept and alternative conventional breeding methods, intra-specific $O$. glaberrima lines were developed starting from three outstanding varieties that are resistant to RYMV: Tog 5681, Tog 5672 and Tog 7291. In this study, we evaluated, through agro-morphological characterization, these intra-specific lines which are adapted to the irrigated lowland cropping system.

\section{Materials and Methods}

\subsection{Plant Materials}

The rice germplasm (Table 1) is composed of intra-specific $O$. glaberrima populations derived from crosses between three outstanding $O$. glaberrima lines Tog 5681, Tog 5672 and Tog 7291 which are resistant to rice diseases, especially blast and RYMV (AfricaRice, 2008; Thiémélé et al., 2010; Sié et al., 2002) and lodging (case of Tog7291) reported by (Futakuchi et al., 2008). The plant material evaluated for their agro-morphological traits comprised 55 genotypes, including 11 intra-specific lines of the $\mathrm{F}_{6}$ generation derived from Tog $5681 \times \operatorname{Tog}$ 5672, and $44 \mathrm{~F}_{6}$ generation lines derived from Tog $5681 \times$ Tog 7291. Five different checks, including three $O$. glaberrima (Tog 5681, Tog 5672 and Tog 7442), and two O. sativa (FKR19 and FKR54) were used as checks. Tog5681 and Tog5672 were used as parents and checks because of their good vegetative growth and resistance to different biotic and abiotic West-African constraints such as blast, RYMV, weed-competitiveness, drought, salinity and iron toxicity; Tog7442 possesses good grain productivity and immunity to the African Rice Gall Midge (AfRGM) (Singh et al., 1996). Concerning the two sativa checks, FKR19 is highly adapted to lowland and irrigated ecologies while FKR54 has high yielding potential.

Table 1. Intra-specific lines derived from crosses between O. glaberrima varieties (Tog5681, Tog5672 and Tog7291) and checks

\begin{tabular}{llllll}
\hline No. & Pedigree & Parents & Class & Source & Generation \\
\hline 1 & S2-4 & Tog $5681 / \operatorname{Tog} 5672$ & Class2 & AfricaRice & F6 \\
2 & S2-5 & $\operatorname{Tog} 5681 / \operatorname{Tog} 5672$ & Class2 & AfricaRice & F6 \\
3 & S2-6 & $\operatorname{Tog} 5681 / \operatorname{Tog} 5672$ & Class2 & AfricaRice & F6 \\
4 & S5-8 & $\operatorname{Tog} 5681 / \operatorname{Tog} 5672$ & Class2 & AfricaRice & F6 \\
5 & S6-9 & Tog $5681 / \operatorname{Tog} 5672$ & Class2 & AfricaRice & F6 \\
6 & S7-1 & Tog 5681/Tog 5672 & Class2 & AfricaRice & F6 \\
\hline
\end{tabular}




\begin{tabular}{|c|c|c|c|c|c|}
\hline 7 & S19-1 & Tog 5681/Tog 5672 & Class2 & AfricaRice & F6 \\
\hline 8 & S19-3 & Tog 5681/Tog 5672 & Class2 & AfricaRice & F6 \\
\hline 9 & S19-4 & Tog 5681/Tog 5672 & Class2 & AfricaRice & F6 \\
\hline 10 & $\mathrm{~S} 21-6$ & Tog 5681/Tog 5672 & Class2 & AfricaRice & F6 \\
\hline 11 & S24-9 & Tog 5681/Tog 5672 & Class2 & AfricaRice & F6 \\
\hline 12 & P1 49-7 & Tog 5681/Tog 5672 & Class1 & AfricaRice & F6 \\
\hline 13 & PL50-4 & Tog 5681/Tog 7291 & Class1 & AfricaRice & F6 \\
\hline 14 & PL50-6 & Tog 5681/Tog 7291 & Class1 & AfricaRice & F6 \\
\hline 15 & PL51-1 & Tog 5681/Tog 7291 & Class 1 & AfricaRice & F6 \\
\hline 16 & PL51-2 & Tog 5681/Tog 7291 & Class 1 & AfricaRice & F6 \\
\hline 17 & PL51-3 & Tog 5681/Tog 7291 & Class 1 & AfricaRice & F6 \\
\hline 18 & PL52-2 & Tog 5681/Tog 7291 & Class1 & AfricaRice & F6 \\
\hline 19 & PL52-4 & Tog 5681/Tog 7291 & Class 1 & AfricaRice & F6 \\
\hline 20 & PL52-5 & Tog 5681/Tog 7291 & Class1 & AfricaRice & F6 \\
\hline 21 & PL52-7 & Tog 5681/Tog 7291 & Class1 & AfricaRice & F6 \\
\hline 22 & PL52-8 & Tog 5681/Tog 7291 & Class1 & AfricaRice & F6 \\
\hline 23 & PL55-2 & Tog 5681/Tog 7291 & Class1 & AfricaRice & F6 \\
\hline 24 & PL55-7 & Tog 5681/Tog 7291 & Class 1 & AfricaRice & F6 \\
\hline 25 & PL57-4 & Tog 5681/Tog 7291 & Class 1 & AfricaRice & F6 \\
\hline 26 & PL57-5 & Tog 5681/Tog 7291 & Class 1 & AfricaRice & F6 \\
\hline 27 & PL57-7 & Tog 5681/Tog 7291 & Class1 & AfricaRice & F6 \\
\hline 28 & PL58-1 & Tog 5681/Tog 7291 & Class1 & AfricaRice & F6 \\
\hline 29 & PL58-2 & Tog 5681/Tog 7291 & Class1 & AfricaRice & F6 \\
\hline 30 & PL62-1 & Tog 5681/Tog 7291 & Class1 & AfricaRice & F6 \\
\hline 31 & PL62-2 & Tog 5681/Tog 7291 & Class1 & AfricaRice & F6 \\
\hline 32 & PL67-1 & Tog 5681/Tog 7291 & Class 1 & AfricaRice & F6 \\
\hline 33 & PL68-1 & Tog 5681/Tog 7291 & Class 1 & AfricaRice & F6 \\
\hline 34 & PL68-6 & Tog 5681/Tog 7291 & Class 1 & AfricaRice & F6 \\
\hline 35 & PL68-8 & Tog 5681/Tog 7291 & Class 1 & AfricaRice & F6 \\
\hline 36 & PL75-2 & Tog 5681/Tog 7291 & Class 1 & AfricaRice & F6 \\
\hline 37 & PL75-3 & Tog 5681/Tog 7291 & Class1 & AfricaRice & F6 \\
\hline 38 & PL75-4 & Tog 5681/Tog 7291 & Class1 & AfricaRice & F6 \\
\hline 39 & PL75-6 & Tog 5681/Tog 7291 & Class1 & AfricaRice & F6 \\
\hline 40 & PL82-7 & Tog 5681/Tog 7291 & Class1 & AfricaRice & F6 \\
\hline 41 & PL85-1 & Tog 5681/Tog 7291 & Class1 & AfricaRice & F6 \\
\hline 42 & PL85-2 & Tog 5681/Tog 7291 & Class 1 & AfricaRice & F6 \\
\hline 43 & PL85-3 & Tog 5681/Tog 7291 & Class 1 & AfricaRice & F6 \\
\hline 44 & PL85-4 & Tog 5681/Tog 7291 & Class 1 & AfricaRice & F6 \\
\hline 45 & PL85-5 & Tog 5681/Tog 7291 & Class 1 & AfricaRice & F6 \\
\hline 46 & PL87-1 & Tog 5681/Tog 7291 & Class 1 & AfricaRice & F6 \\
\hline 47 & PL87-2 & Tog 5681/Tog 7291 & Class1 & AfricaRice & F6 \\
\hline 48 & PL87-3 & Tog 5681/Tog 7291 & Class 1 & AfricaRice & F6 \\
\hline
\end{tabular}




\begin{tabular}{llllll}
\hline 49 & PL87-4 & $\operatorname{Tog} 5681 / \operatorname{Tog} 7291$ & Class1 & AfricaRice & F6 \\
50 & PL87-5 & $\operatorname{Tog} 5681 / \operatorname{Tog} 7291$ & Class1 & AfricaRice & F6 \\
51 & PL87-6 & $\operatorname{Tog} 5681 / \operatorname{Tog} 7291$ & Class1 & AfricaRice & F6 \\
52 & PL87-8 & $\operatorname{Tog} 5681 / \operatorname{Tog} 7291$ & Class1 & AfricaRice & F6 \\
53 & PL88-3 & $\operatorname{Tog} 5681 / \operatorname{Tog} 7291$ & Class1 & AfricaRice & F6 \\
54 & PL92-1 & $\operatorname{Tog} 5681 / \operatorname{Tog} 7291$ & Class1 & AfricaRice & F6 \\
55 & PL92-4 & $\operatorname{Tog} 5681 / \operatorname{Tog} 7291$ & Class1 & AfricaRice & F6 \\
56 & Tog 5672(O. glaberrima $)$ & - & Check 1 & AfricaRice & \\
57 & Tog 5681(O. glaberrima $)$ & - & Check 2 & AfricaRice & \\
58 & Tog 7442(O. glaberrima $)$ & - & Check 3 & AfricaRice & \\
59 & FKR 19 (O. sativa $)$ & MASHURI/ IET 1444 & Check 4 & AfricaRice & \\
60 & FKR 54(O. sativa $)$ & - & Check 5 & AfricaRice & \\
\hline
\end{tabular}

\subsection{Establishment of Experimental Trial}

The experiment was established in the 2011 cropping season on the experimental site of AfricaRice located at Ouedeme (6 $6^{\circ} 42^{\prime} 46^{\prime \prime} \mathrm{N}$ and $1^{\circ} 41^{\prime} 07^{\prime \prime} \mathrm{E}$ at $21 \mathrm{~m}$ altitude), District of Lokossa in Benin (Figure 1). The field was mechanically ploughed, harrowed and leveled, and the trial was laid out using the Augmented Block Design (Federer, 1956). There were five blocks separated by $1 \mathrm{~m}$ with 16 genotypes randomized in each block (11 intra-specific $O$. glaberrima lines and 05 checks). After sowing at a spacing of $20 \times 20 \mathrm{~cm}$ within each plot $(5 \mathrm{x}$ $1 \mathrm{~m}^{2}$ ) comprising five rows for each genotype, seedlings were thinned to one plant per hill in the field. Fertilizers applied included NPK 15-15-15 as basal application at the rate of $100 \mathrm{~kg} \mathrm{ha}^{-1}$ during land preparation, and urea applied as top dressing at the rate of 35 at tillering and $65 \mathrm{~kg} / \mathrm{ha}$ at heading. Hand weeding was carried out at 21 days after sowing (DAS) and at heading just before urea application.

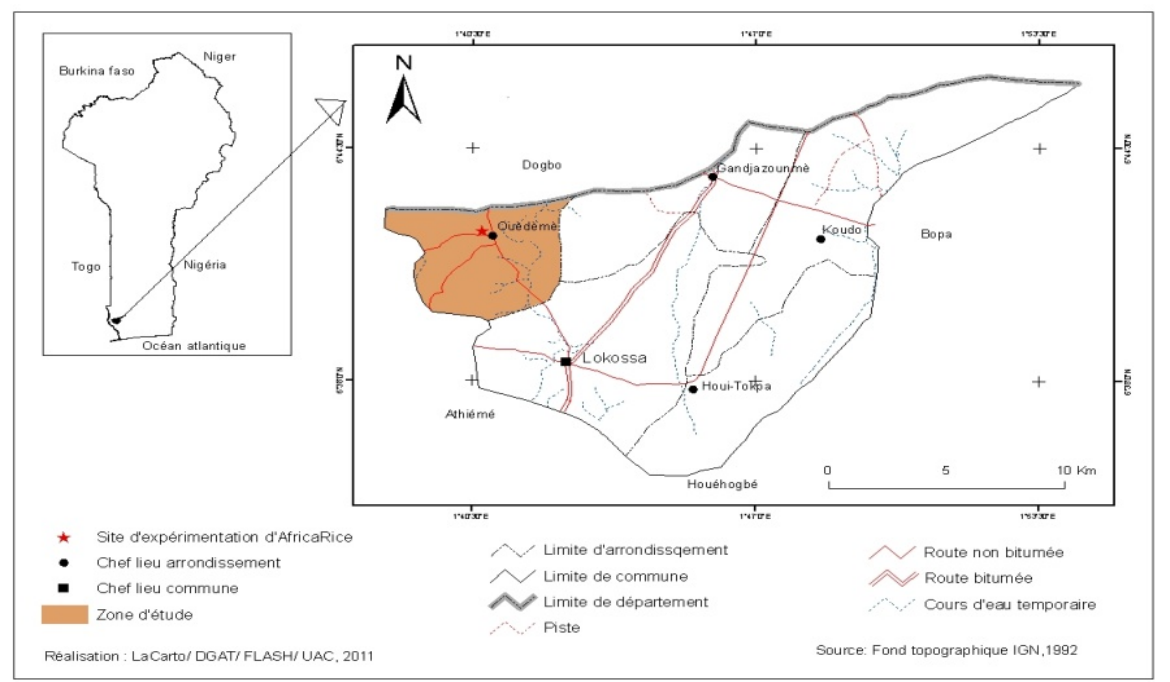

Figure 1. Location of the experimental farm at Ouedeme (Lokossa/Benin)

\subsection{Phenotypic Evaluation}

Each of the different intra-specific classes was evaluated using 18 agro-morphological quantitative traits. Data were collected from the three middle rows of each plot and average of each quantitative variables were used for the analysis. Plant agro-morphological evaluation was carried out using the Standard Evaluation System (SES) for Rice of the International Rice Research Institute (IRRI, 2002). These variables are presented in Table 2. 
Table 2. Quantitative characters measured on the 55 intra-specific $O$. glaberrima lines and checks

\begin{tabular}{llcclc}
\hline S/N. & Characters & Code & S/N. & Characters & Code \\
\hline 1 & Days to 50\% heading & 50\% Hdg & 10 & Panicle length & PnL \\
2 & Tiller number at 60 DAS & Ti 60DAS & 11 & Primary panicle branches & PPnBr \\
3 & Number of panicles & NPn & 12 & Secondary panicle branches & SPnBr \\
4 & Plant height at 30 DAS & HT 3ODAS & 13 & Weight of 1000 grains & W1000Gr \\
5 & Plant height at 60 DAS & HT 60DAS & 14 & Number of full grains & FullGr \\
6 & Plant height at maturity & HT mat & 15 & Panicle fertility & Pnfert \\
7 & Leaf length & LL & 16 & Grain length & GrL \\
8 & Leaf width & LW & 17 & Grain width & GrW \\
9 & Diameter & Diam & 18 & Days to maturity & Mat \\
\hline
\end{tabular}

\subsection{Statistical Analyses}

Average and standard deviation were calculated on each quantitative character. Variation in various measured characters was tabulated and plotted using the Microsoft Excel Program. Comparison was also made between intra-specific crossing groups and checks. Phenotypic associations were assessed between the 55 intra-specific $O$. glaberrima lines and checks using correlation coefficient, principal component analysis (PCA) and cluster analysis. Differences observed between clusters were evaluated through Analysis of Variance (ANOVA). These data analyses were evaluated using Statistica and SPSS software.

\section{Results}

\subsection{Variation within Intra-specific O. glaberrima Classes and Checks}

The intra-specific $O$. glaberrima evaluated displayed a considerable variation for the measured quantitative characters. There was highly significant variation between the two different classes and checks in plant height at 60 DAS, leaf dimensions, weight of 1000 grains, panicle fertility and grain length (Figures 2-7). Class 1, including the majority $(83.63 \%)$ of the studied genotypes contains lines characterized by very well developed leaves and a wide range of variation within the measured characters. In opposite, intra-specific lines in from class $2(16.36 \%)$ possess medium to high plant height and relatively long grains, fertile and productive panicles.

The variation observed among the checks showed that $O$. glaberrima varieties, especially Tog5681, have good vegetative growth (expressed by high tillering, plant height and developed leaf area) whereas sativa checks, especially FKR 54, had important yielding characters (panicle fertility, grain length and grain weight). The inheritance of the vegetative characters was observed in class 1 because of the rapid vegetative growth of Tog7291 whereas, intra-specific in class 2 exhibited good inheritance of productive characters.

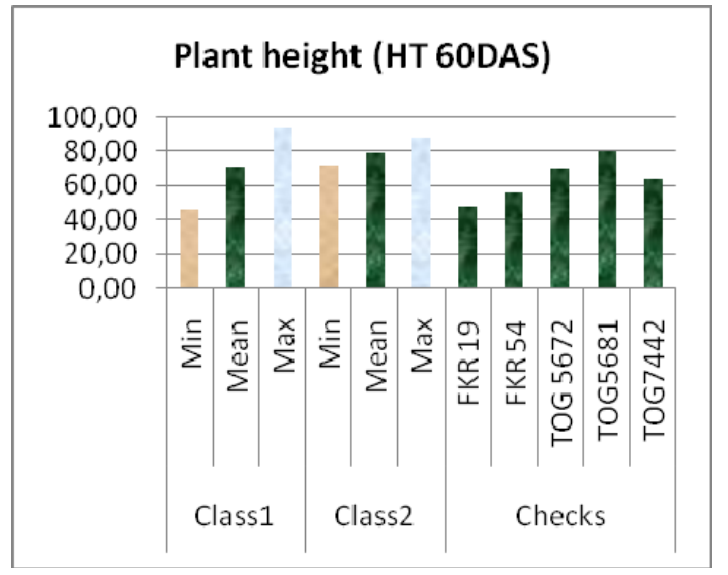

Figure 2. Variation in plant height in intra-specific lines and checks

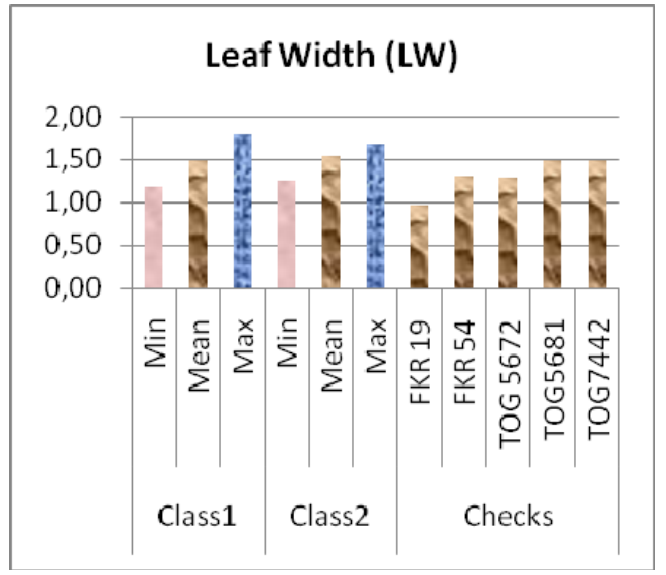

Figure 3. Variation in leaf width for intra-specific and checks 


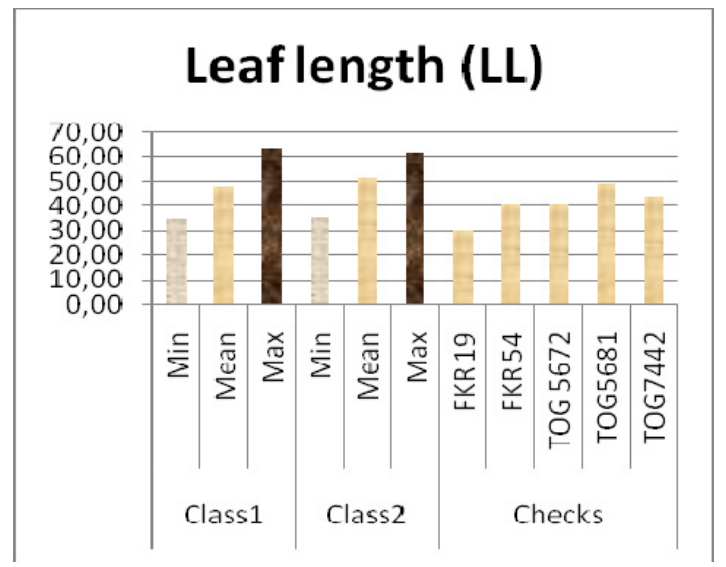

Figure 4. Variation in leaf length for intra-specific lines and checks

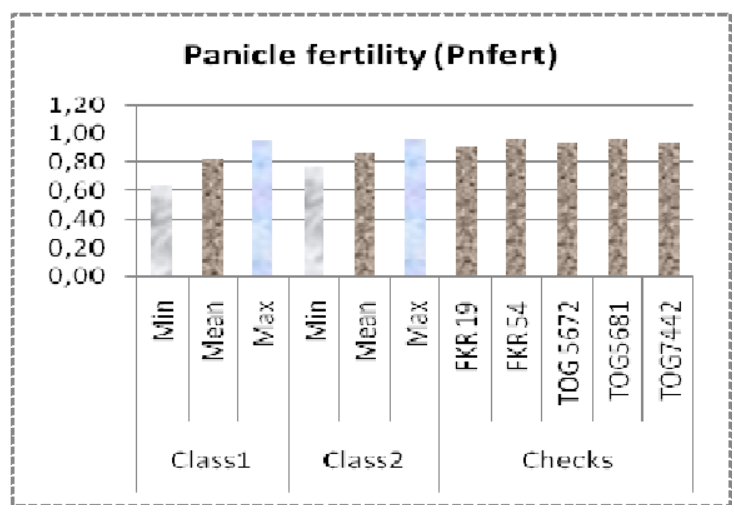

Figure 6. Variation in panicle fertility for intra-specific and checks

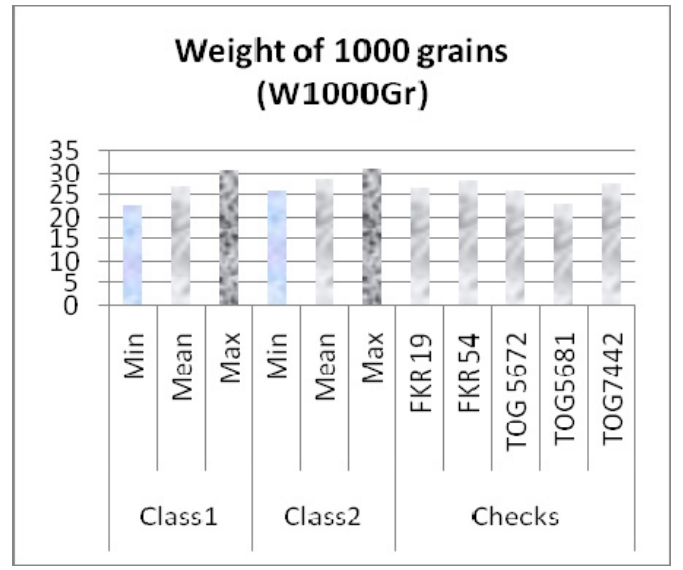

Figure 5. Variation in grain weight for intra-specific lines and checks

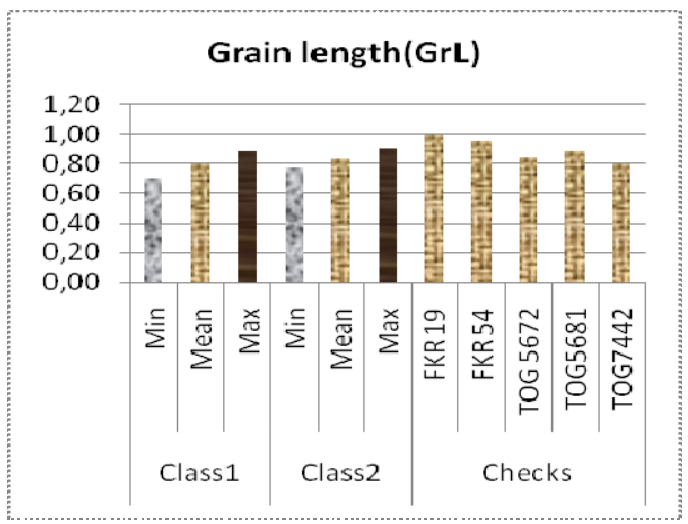

Figure 7. Variation in grain length for intra-specific and checks

\subsection{Phenotypic Association and Relationship between Intra-specific O. glaberrima Lines}

The correlation matrix for all traits is established in Table 3. Irrespective of measuring time, plant height had always a significant and positive correlation with both leaf length and width $(0.56 \leq \mathrm{r} \leq 0.57)$. Highly significant correlations were also observed between any two of the plant heights measured in different time $(0.63 \leq \mathrm{r} \leq 0.89)$ and between heading and maturity $(r=0.92)$; leaf length and leaf width $(r=0.78)$; full grain and both primary and secondary panicle branches $(r=0.54$ and 0.67 , respectively). The PCA performed on the basis of 14 quantitative traits, out of the 18 measured, showed positive correlation with axis 1 . The projection of individuals in the two first axes (1 and 2) showed a wide distribution of intra-specific lines (Figure 8 and 9). The relative discriminating power of these axes (Eigen values) was highest for axis 1 (4.77) and lowest for axis 2 (2.04). PC1 $(34.08 \%$ of the total variation) was mostly correlated with plant height, leaf width, leaf length, panicle length and number of full grains. This axis mainly expressed the plant vegetative growth and grain fertility. The second axis (PC2) was mostly correlated with date of heading, maturity and weight of 1000 grains, i.e. cycle duration and grain productivity. Intra-specific lines located on the positive side of axis 1 (Figure 9) and particularly those joined together in group 1 (especially S19-3, PL55-2, PL51-3 and S6-9) are characterized by raised heights, broad leaves and number of full grains contrary to those located on the opposite side, which include sativa checks, especially FKR19. On the second axis, individuals (e.g. PL87-2 and PL75-2) have longer plant cycle and higher grain productivity contrary to those located on the opposite side (e.g. S21-6 and Tog5672, one of the $O$. glaberrima checks) which are earlier maturing.

The two parents Tog 5681 and Tog 5672 also used as checks exhibited lower vegetative development and grain fertility than intra-specific lines in group1. This low vegetative growth was even more pronounced in both sativa checks (FKR19 and FKR54) and in Tog7442 that are closer to individuals from Group 2. 
Table 3. Correlation between the 18 measured quantitative characters

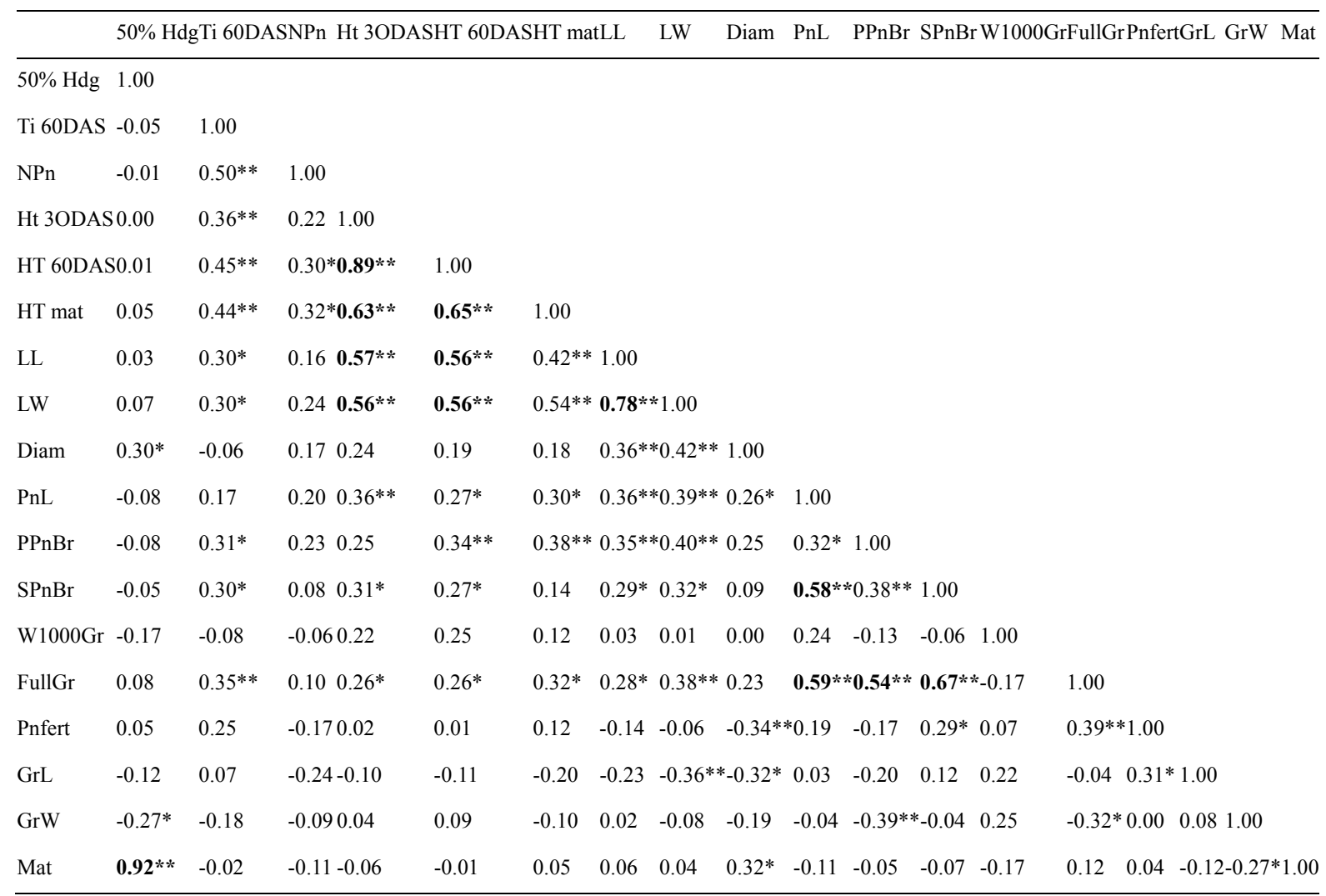

*significant at $\mathrm{P} \leq 0.05$ and **significant at $\mathrm{P} \leq 0.01$.

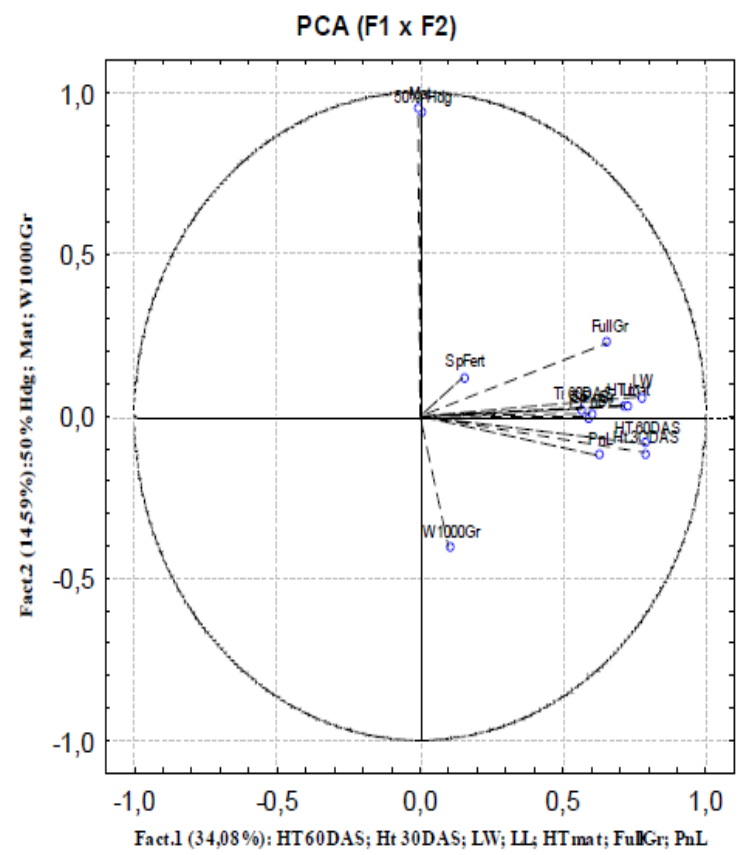

Figure 8. Distribution of quantitative traits in axes 1and 2

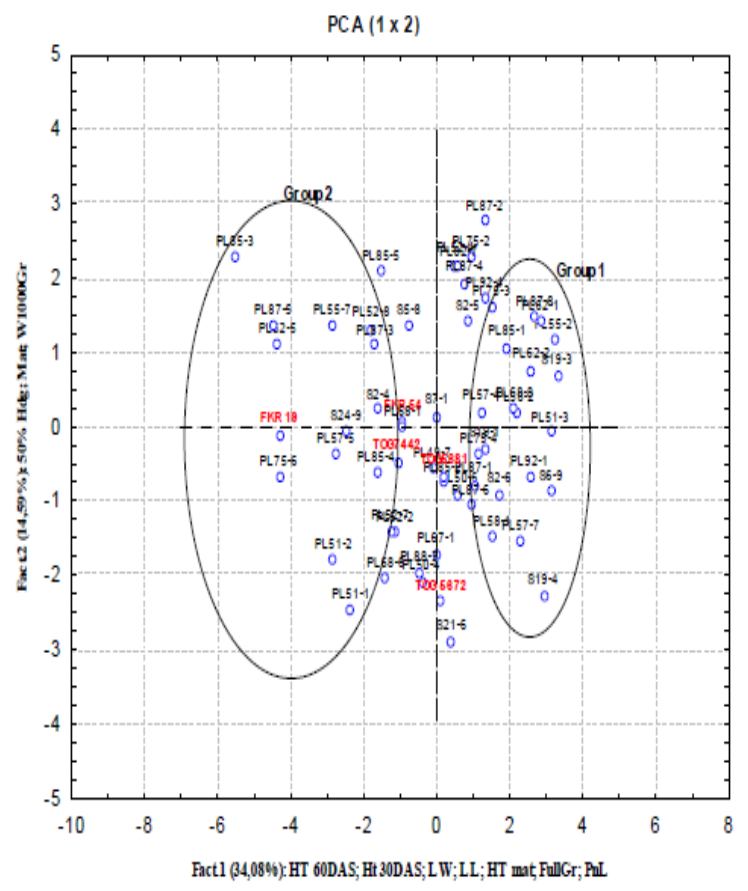

Figure 9. Projection of intra-specific lines and checks in axes 1 and 2 


\subsection{Evaluation and Grouping of Intra-specific O. glaberrima Lines}

The dendrogram (Figure 10) established on the basis of the same quantitative traits used for the PCA showed that intra-specific lines were divided into two major groups which were then subdivided into five sub-groups. Genotypes from clusters 1,2 , and 3 possess about $24 \%$ of similarity whereas genotypes from clusters 4 and 5 had about $20 \%$ of similarity. Analysis of variance performed on these groups (Table 4), showed highly significant differences between all traits except cycle duration characters which were not significant at $\mathrm{P} \leq 0.05$. A wide range of variation was exhibited for major characters such as tillering, plant height, leaf length and leaf width, panicle length, primary and secondary panicle branching, grain weight, panicle fertility and number of full grains. These characters are the most important for showing differences between groups. At the vegetative stage, intra-specific lines from group 4 had the best average performance for tillering ability, leaf length $(50.52 \pm 5.98$ $\mathrm{cm})$, leaf width $(15.9 \pm 1.0 \mathrm{~mm})$ and plant height especially at maturity $(139.75 \pm 8.13 \mathrm{~cm})$. The best intra-specific lines recorded in this group were PL87-1 and PL85-1 for plant height, PL92-1 for leaf length, PL87-8 for leaf width and PL87-8 for tiller number. This group does not include any of the checks used and its genotypes present higher phenotypic characters than those of most of the checks. Moreover, at the reproductive stage, genotypes belonging to group5 were the most productive intra-specific $O$. glaberrima lines. This productivity was expressed especially through panicle characteristics such as panicle length $(25.27 \pm 1.46 \mathrm{~cm})$, primary and secondary panicle branches $(14.49 \pm 0.20$ and $24.53 \pm 5.30)$ respectively, number of full grains $(150.21 \pm 8.72)$ and panicle fertility $(0.86 \pm 0.05)$. Weight of 1000 grains $(28.20 \pm 1.70 \mathrm{~g})$ was higher in group 3 . There was a close association between checks and intra-specific lines from group 1 (Tog5681 and FKR54) and group 3 (Tog7442 and FKR 19).

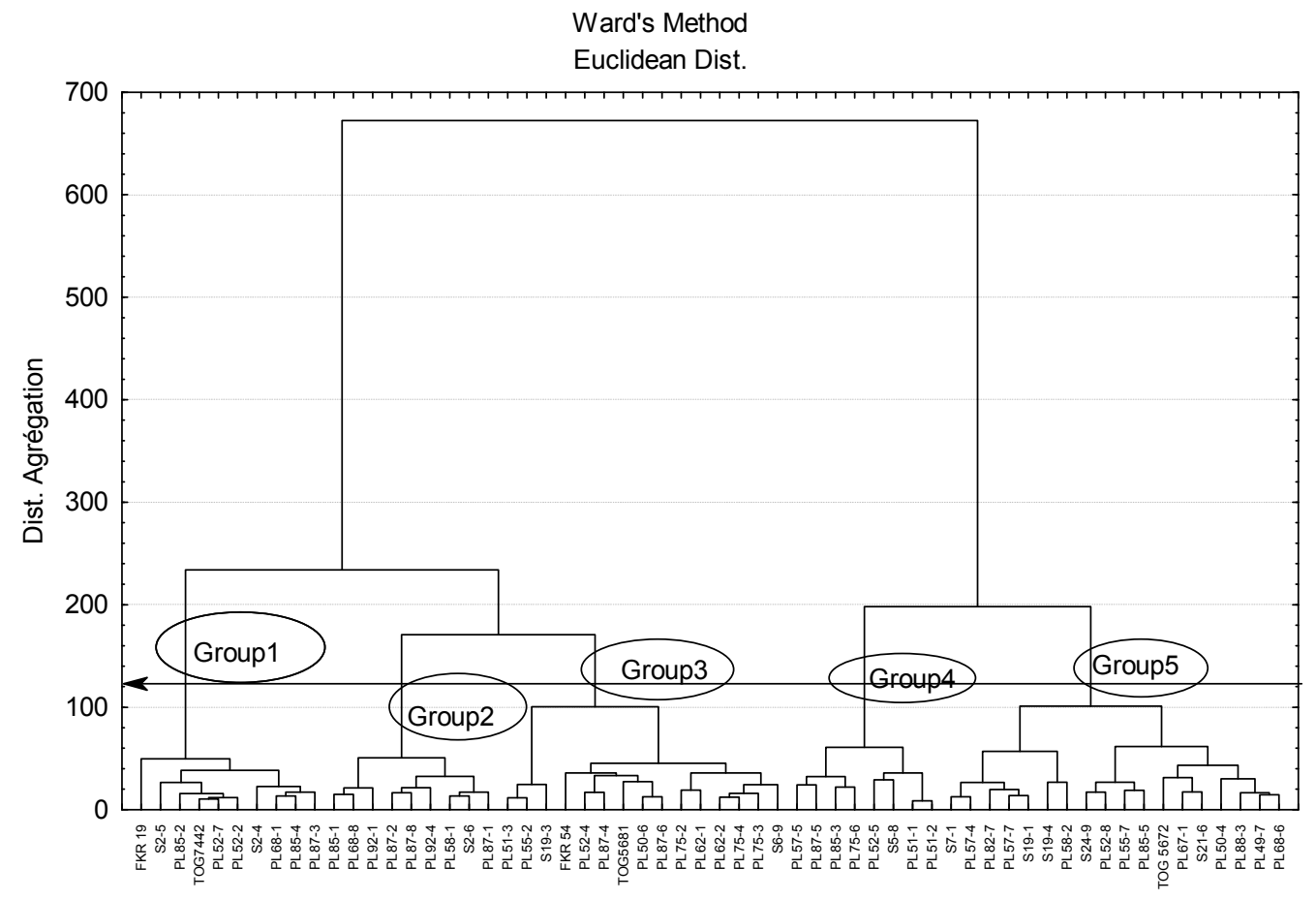

Figure 10. Hierarchical clustering of 55 intra-specific $O$. glaberrima lines and checks based on quantitative characters

\section{Discussion}

The developed intra-specific populations of $O$. glaberrima present some interesting potentialities for WCA ecosystems. The genotypes tested showed variation with respect to the evaluated traits. Some traits, e.g. total number of tillers, plant height, leaf dimensions, panicle length, number of full grains and panicle ramifications greatly influence the agro-phenotypic performances of the genotypes evaluated. The comparative analysis of the variation between the most distinctive characters within the two intra-specific classes showed that important 
discriminating vegetative characters, (e.g. plant height and leaf width and leaf length associated to productive characters especially panicle fertility, grain weight and grain length) were more widely inherited by intra-specific lines in class 2 than those in class 1 . The domination of the vegetative characters was also observed more in the O. glaberrima checks than in the sativa (FKR19 and FKR54) which were less powerful for these characters but higher for the yielding components. These results confirm the weed-competitiveness of $O$. glaberrima through its high plant vigor, high tillering ability, and large specific leaf areas opening to the plant canopy (WARDA, 1996; Dingkuhn et al., 1999; Rodenburg, 2009; Moukoumbi et al., 2011).

Table 4. ANOVA test and means values performed on the five intraspecific $O$. glaberrima groups resulting from hierarchical clustering

\begin{tabular}{|c|c|c|c|c|c|c|c|c|c|c|c|c|c|c|}
\hline Groups & $50 \% \mathrm{Hdg}$ & Ti 60DAS & HT 3ODAS & HT 60DAS & HT mat & LL & LW & $\mathrm{PnL}$ & $\mathrm{PPnBr}$ & $\mathrm{SPnBr}$ & FullGr & Mat & W1000Gr & Pnfert \\
\hline & 106.42 & 5.68 & 41.55 & 65.25 & 117.55 & 42.89 & 1.37 & 24.01 & 12.66 & 16.06 & 115.92 & 134.2 & 27.54 & 0.87 \\
\hline G1 & \pm 3.88 & \pm 1.52 & \pm 3.84 & \pm 7.77 & \pm 10.55 & \pm 6.05 & \pm 0.14 & \pm 1.34 & \pm 2.10 & \pm 5.07 & \pm 8.56 & \pm 4.93 & \pm 1.43 & \pm 0.07 \\
\hline \multirow[t]{2}{*}{ G2 } & 108.78 & 3.54 & 37.73 & 59.46 & 109.8 & 43.02 & 1.37 & 22.03 & 11.30 & 9.63 & 75.78 & 136.89 & 27.31 & 0.77 \\
\hline & \pm 5.14 & \pm 0.92 & \pm 6.79 & \pm 9.88 & \pm 9.17 & \pm 5.77 & \pm 0.15 & \pm 1.65 & \pm 1.76 & \pm 4.01 & \pm 11.15 & \pm 6.43 & \pm 2.32 & \pm 0.08 \\
\hline \multirow[t]{2}{*}{ G3 } & 106.00 & 6.65 & 55.26 & 77.80 & 129.50 & 51.77 & 1.53 & 23.98 & 11.80 & 14.47 & 91.79 & 132.85 & 28.20 & 0.83 \\
\hline & \pm 4.55 & \pm 1.32 & \pm 7.42 & \pm 8.17 & \pm 7.55 & \pm 6.71 & \pm 0.07 & \pm 1.88 & \pm 1.56 & \pm 8.24 & \pm 7.17 & \pm 6.66 & \pm 1.70 & \pm 0.07 \\
\hline \multirow[t]{3}{*}{ G4 } & 109.11 & 7.50 & 60.44 & 80.98 & 139.75 & 50.52 & 1.59 & 24.45 & 13.28 & 16.40 & 123.36 & 136.67 & 27.42 & 0.85 \\
\hline & \pm 4.28 & \pm 1.49 & \pm 6.28 & \pm 4.40 & \pm 8.13 & \pm 5.98 & \pm 0.10 & \pm 1.11 & \pm 1.12 & \pm 2.70 & \pm 11.04 & \pm 5.20 & \pm 2.03 & \pm 0.07 \\
\hline & 107.98 & 6.44 & 51.38 & 74.39 & 127.61 & 51.13 & 1.56 & 25.27 & 14.49 & 24.53 & 150.21 & 136.46 & 26.42 & 0.86 \\
\hline \multirow[t]{2}{*}{ G5 } & \pm 3.62 & \pm 1.60 & \pm 7.01 & \pm 10.10 & \pm 11.44 & \pm 6.85 & \pm 0.14 & \pm 1.46 & \pm 2.00 & \pm 5.30 & \pm 8.72 & \pm 4.42 & \pm 2.12 & \pm 0.05 \\
\hline & 107.50 & 6.04 & 49.40 & 71.90 & 125.00 & 48.17 & 1.49 & 24.11 & 12.85 & 17.06 & 114.93 & 135.30 & 27.33 & 0.84 \\
\hline \multirow[t]{2}{*}{ All Groups } & \pm 4.26 & \pm 1.82 & \pm 9.99 & \pm 11.09 & \pm 13.21 & \pm 7.36 & \pm 0.15 & \pm 1.79 & \pm 2.09 & \pm 7.39 & \pm 27.90 & \pm 5.55 & \pm 1.96 & \pm 0.07 \\
\hline & & & & & & & 0.0000 & & & 0.00000 & & 0.2959 & & \\
\hline$P$ & $0.31945 \mathrm{NS}$ & $0.0000 * * *$ & $0 * * *$ & $0.0000 * * *$ & 0 *** & $0.0005 * * *$ & $* * *$ & $0.0001 * * *$ & $0.0003 * * *$ & $* * *$ & $0 * * *$ & NS & $0.18678 \mathrm{NS}$ & $0.01131 *$ \\
\hline
\end{tabular}

PCA and hierarchical clustering generated from similarity or genetic distance matrices provided an overall pattern of variation as well as the degree of relatedness among the genotypes. In addition, the PCA confirmed the contributions of the discriminating traits observed between the two classes when intra-specific lines were plotted on the two axes (1 and 2). The ANOVA test performed after the hierarchical cluster analysis showed many discriminating traits including the first ones identified. The implication of this result is that if selection is to be made between cluster groups for a future breeding exercise, plant height, leaf width, leaf length, panicle fertility, panicle length and panicle ramifications should be given high priorities. Indeed, because O. glaberrima is highly adapted to African environments, these intra-specific lines formed the most interesting for morphological (group 4) and agronomic (group 5) performance that have a better capacity for adaptation to the diversity of irrigated and lowland rice systems. Important correlation observed between vegetative characters (plant height and leaf dimensions) and reproductive characters (panicle length, primary and secondary panicles branches) through phenotypic correlation and PCA, highlighted the link between photosynthetic activity and grain productivity. These characters may be exploited hereafter or considered as breeding components to develop good intra-specific varieties.

O. glaberrima showed mostly higher yield than $O$. sativa under unfavorable environments but inferior yields in favorable conditions, (http://ricecongress.com/previous/pdflink/3936.pdf). However, the number of spikelets before grain shattering was not lower in O. glaberrima than in O. sativa at any level of fertilizer input. The inferior yield of $O$. glaberrima in the favorable environments could be due to grain shattering and/or higher incidence of lodging, which may be specific characters of $O$. glaberrima. Yield of $5-6 \mathrm{tha}^{-1}$ (Futakuchi \& Sié, 2009; Sié et al, 2012) were obtained in O. glaberrima in the dry season, when plants were shorter, had higher photoperiod sensitivity and avoided lodging. This is true of intra-specific lines in group 1 (e.g. the sativa check FKR19 and the O. glaberrima Tog7442 which is resistant to lodging) but which nevertheless present low 
yielding ability compare to lines in group 5. In general, grain productivity and grain shattering were improved for the majority of intra-specific lines evaluated. However, seed dormancy is one of the undesirable characters recorded. The use of Tog5681 as a relative female enhanced the development of maternal effect in intra-specific genotypes as it was the case for lowland NERICA varieties (Sie, 2005). If resistance to lodging and grain shattering can be improved through intra-specific breeding, promising $O$. glaberrima varieties may have good yield performance under harsh environments with responsiveness to management inputs. This will open new perspectives for the exploitation of $O$. glaberrima germplasm in crop improvement. In rice, wide crosses have been extensively used to transfer useful traits through interspecific breeding programs (Brar \& Khush, 1997). Many advanced lines have been obtained in various genetic backgrounds, but the exact mechanisms of such interspecific transfers remain unknown. Given the recently published work cited above, some of the newly created phenotypic diversity raise the potential for the valorization of the African rice.

\section{Conclusions}

Intra-specific lines developed present more variation and a good agro-morphological diversity within the two classes of $O$. glaberrima lines. The hierarchical clustering established showed an interesting grouping of lines according to their agro-phenotypic characters. Lines in group4 of the dendrogram present better vegetative performance whereas those in group 5 present better yielding ability than the sativa checks. Such groupings are useful to breeders in identifying possible $O$. glaberrima that may be used as "parents" in breeding for any of the morphological traits that were studied.

\section{Acknowledgment}

The authors are grateful to Africa Rice Center (Africa Rice) and to the International Foundation for Science (IFS) for funding and for facilitating this study.

\section{References}

Africa Rice Center (WARDA)/FAO/SAA. (2008). NERICA®: the New Rice for Africa-a Compendium. EA Somado, RG Guei and SO Keya (eds.). Cotonou, Benin: Africa Rice Center (WARDA); Rome, Italy: FAO; Tokyo, Japan: Sasakawa Africa Association. p. 210.

Agnoun, Y. M., Sié, G., Djedatin, K. N., Dramé, B., Toulou, S. A., Ogunbayo, K. A., ...Vodouhè, R. S. (2012). Molecular profiling of interspecific lowland rice progenies resulting from crosses between TOG5681 and TOG5674 (Oryza glaberrima) and IR64 (Oryza sativa). Accepted in International Journal of Biology (March 7, 2012).

Brar, D. S., \& Khush, G. S. (1997). Plant Mol Biol, 35(1-2), 35-47. http://dx.doi.org/10.1023/A:1005825519998

Dingkuhn, M., Johnson, D. E., Sow, A., \& Audebert, A. (1999). Relationships between upland rice canopy characteristics and weed competitiveness. Field Crops Research, 61, 79-95. http://dx.doi.org/10.1016/S0378-4290(98)00152-X

FAO. (2004). Special description of Oryza sativa.

FAO. (2009). Food and Agricultural Organization of the United Nations. Quarterly Bulletin of Statistics (FAOSTAT).

Federer, W. T. (1956). Augmented designs. Hawaiian planter's Rec., 55, 191-208.

Fofana, B. \& Rauber, R. (2000). Weed suppression ability of upland rice under low-input condition in West Africa. Weed Res., 40, 271-280. http://dx.doi.org/10.1046/j.1365-3180.2000.00185.x

Futakuchi, K., Fofana, M., \& Moussa, Sié. (2008). Varietal Differences in lodging Resistance of African Rice (Oryza glaberrima). Asian Journal of Plant Sciences. http://dx.doi.org/10.3923/ajps.2008.569.573

Futakuchi, K., \& Sié, M. (2009). Better exploitation of African Rice (Oryza glaberrima Steud.) in varietal development for resource-Poor Farmers in West and Central Africa. Agricultural Journal, 4(2), 96-102.

IRRI. (2002). Standard Evaluation system for rice 5è edition, Manila Philippines.

JOHO, Y., Kenji, O., Naoyoshi, K., \& Jun-Ichi, S. (2008). Growth Responses of Seedlings in Oryza glaberrima Steud. to Short-term Submergence in Guinea, West Africa. JARQ ,42(3), 157-162.

Jones, M. P., Dingkuhn, M., Aluko, G. K., \& Semon, M. (1997). Interspecific Oryza sativa L. x O. glaberrima Steud. progenies in upland rice improvement. Euphytica, 92, 237-246. http://dx.doi.org/10.1023/A:1002969932224

Marie, N. N., Kassa, S., Moussa, S., Mamadou, C., Blandine, F., \& Monty, J. (2008). Molecular profiling of 
interspecific lowland rice populations derived from IR64 (Oryza sativa) and Tog5681 (Oryza glaberrima). African Journal of Biotechnology, 7(23), 4219-4229.

Mohapatra, S. (2011). Beware of bronzing. Rice faces its own kryptonite-iron toxicity-and AfricaRice is finding a way to help rice survive it. Rice Today, 1 .

Mohapatra, S. (2010). Pockets of Gold. Rice Today. pp. 32-33.

Moukoumbi, Y. D., Sie, M., Vodouhe, R., Bonou, W., Toulou, B., \& Ahanchede, A. (2011). Screening of rice varieties for their weed competitiveness. African Journal of Agricultural Research , 6(24), 5446-5456.

Rodenburg, J., Kazuki, S., Romain, G. K., Amadou, T., Mariame, M., \& Paul, K. (2009). Weed competitiveness of the lowland rice varieties of NERICA in the southern Guinea Savanna. Field Crops Research, 114, 411-418. http://dx.doi.org/10.1016/j.fcr.2009.09.014

Sahrawat, K. L., \& Sika, M. (2002). Comparative tolerance of $O$. sativa and $O$. glaberrima rice cultivars for iron toxicity in West Africa. Int. Rice Res. Notes, 27, 30-31.

Sarla, N., \& Mallikarjuna, S. B. P. (2005). Oryza glaberrima: A source for improvement of Oryza sativa. Current science, 89, 6-9.

Sie. M, Kayode, S., Koichi, F., Baboucarr, M., Semon, M., Raymond, V., ... Karim, T. (2012). Towards a rational Use of African Rice (Oryza glaberrima Steud.) for Breeding in Sub-Saharan Africa. Genes, Genomes and Genomics. p.7.

Sie, M. S., Dogbe, Y., \& Coulibaly, M. (2005). Selection of interspecific hybrids (O. sativa $x$ O. glaberrima or lowland NERICAs) and intraspecifics adapted to rained lowland growing conditions. Int. Rice Comm. Newslett., 54, 47-51.

Sié, M., Blaise, K., Drissa, S., \& Yonnelle, D. (2002). Selection of intraspecific (Oryza sativa $\times$ O. sativa) and inter-specific $(O$. sativa $\times O$. glaberrima) lines for their tolerance to blast in Burkina Faso. Institut de l'environnement et de Recherches Agricoles (I.N.E.R.A.) 01 B.P. 910 Bobo-Dioulasso 01. pp. 23-37.

Singh, B. N., Maji, A. T., Paul, C., William, C., \& Ukwungwu, M. N. (1996). Utilisation of Oryza glaberrima genetic resources for lowland rice improvement. In: Jones MP, Dingkuhn M, Johnson DE, Fagade SO, editors. Interspecific hybridization: progress and prospects. Bouaké (Côte d'Ivoire): West Africa Rice Development Association. pp. 177-187.

Thiémélé, D., Arnaud, B., Marie-Noelle, N., Sophie, C., Yacouba, S., Sévérin, A., Alain, G., \& Laurence, A. (2010). Identification of a second major resistance gene to rice yellow mottle virus RYMV2, in the African cultivated Rice species, O.glaberrima. http://dx.doi.org/10.1007/s00122-010-1300-2

WARDA. (1996). Annual Report. pp.7-17. 